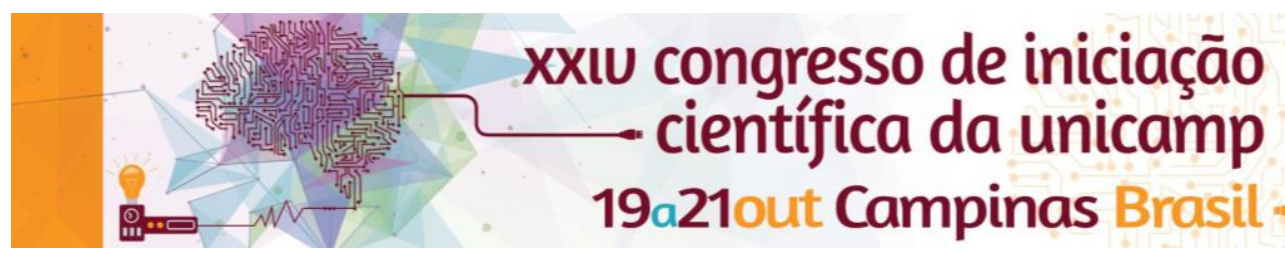

\title{
Análise de Sensibilidade do Dimensionamento do Número de Posições de Estacionamento em Terminais Aeroportuários
}

\section{Carlos Alberto Bandeira Guimarães, Erika Shiba*}

\section{Resumo}

Com o intuito de analisar o dimensionamento de posições de estacionamento de aeronaves de passageiros em terminais aeroportuários, desenvolveu-se este Projeto de Pesquisa. Dados sobre terminais de portes distintos foram considerados para a obtenção resultados representativos. Através de informações sobre a ocupação de posições de aeronaves, realizou-se o dimensionamento de cada terminal por meio de um modelo determinístico de filas. O resultado correlaciona a situação ideal e o cenário atual.

\section{Palavras-chave}

Terminal Aeroportuário, Hora de Pico, Posições de Estacionamento.

\section{Introdução}

O transporte aeroviário representa, atualmente, o meio mais seguro, rápido e adequado de transporte de acordo com a Agência Nacional de Aviação Civil (ANAC). No cenário nacional, os brasileiros buscam, cada dia mais, o transporte aéreo. Além disso, após a intensificação do processo de globalização datada do século $X X$, as viagens internacionais tornaram-se recorrentes. $O$ número de posições de estacionamento de aeronaves em pátios está diretamente atrelado ao potencial do aeroporto. O objetivo deste projeto é desenvolver uma análise do dimensionamento do número de posições de estacionamento de aeronaves em pátios de terminais aeroportuários visando melhorar a logística, reduzindo os tempos de espera das aeronaves.

\section{Resultados e Discussão}

Os terminais aeroportuários considerados neste projeto são: Aeroporto Internacional de Salvador (SSA), Aeroporto Santos Dumont (SDU) e Aeroporto Internacional de Brasília (BSB), pois representam terminais de pequeno, médio e grande porte respectivamente, em relação ao volume de voos diários. Realizou-se o levantamento de dados de ocupação das aeronaves a partir de dados da Empresa Brasileira de Infraestrutura Aeroportuária (Infraero) e do sistema FlightStats. Em seguida, dimensionou-se cada terminal aeroportuário por meio de um modelo determinístico de filas.

Tabela 1. Quadro resumo do dimensionamento do número de posições de estacionamento para o Aeroporto Internacional de Salvador.

\begin{tabular}{|c|c|c|c|}
\hline $\begin{array}{c}\text { Posições } \\
\text { de } \\
\text { estaciona } \\
\text { mento }\end{array}$ & $\begin{array}{c}\text { Tempo médio } \\
\text { de espera } \\
\text { (min/aeronave) }\end{array}$ & $\begin{array}{c}\text { Tempo } \\
\text { máximo } \\
\text { de espera } \\
\text { (min) }\end{array}$ & $\begin{array}{c}\text { Ocupação } \\
\text { média das } \\
\text { plataformas } \\
\text { (min) }\end{array}$ \\
\hline 9 & 125,90 & 260,00 & 76,40 \\
\hline 10 & 77,40 & 184,00 & 73,80 \\
\hline 11 & 39,70 & 124,00 & 70,00 \\
\hline 12 & 21,40 & 79,00 & 64,20 \\
\hline 13 & 10,50 & 52,00 & 59,20 \\
\hline 14 & 5,50 & 27,00 & 55,00 \\
\hline 15 & 2,20 & 20,00 & 51,30 \\
\hline 16 & 0,70 & 18,00 & 48,10 \\
\hline 17 & 0,30 & 15,00 & 45,30 \\
\hline $1019146 / p 10-2016-51840$ & &
\end{tabular}

\begin{tabular}{|l|l|l|l|}
\hline 18 & 0,10 & 9,00 & 42,80 \\
\hline 19 & 0,00 & 0,00 & 40,50 \\
\hline
\end{tabular}

\section{Conclusões}

O terminal de pequeno porte conta com 11 portões. Analisando-se o dimensionamento, pode-se concluir que o número ideal é de 19 portões. Desta forma, as aeronaves não aguardariam para estacionar, melhorando a logística do transporte. O terminal de médio porte possui 8 portões e o ideal seriam 24. Para o terminal de grande porte, o ideal seriam 54 portões, ao passo que há apenas 11 .

\section{Agradecimentos}

Agradeço ao Prof. Dr. Carlos Alberto Guimarães pela orientação deste Projeto de Pesquisa e pela oportunidade de realizá-lo. E, também, a Universidade Estadual de Campinas pelo incentivo à inserção no âmbito científico.

${ }^{1}$ Ashford, N. J.; Mumayiz, S. A.; Wright, P. H. Airport Engineering: planning, design, and development of 21 st-century airports. 4th ed., Hoboken: John Wiley \& Sons, Inc., 2011.

${ }^{2}$ Horonjeff, R.; Mckelvey, F. X.; Sproule, W. J.; Young, S. B. Planning and Design of Airports. 5th ed., McGraw-Hill, 2010. 